NIST Special Publication 1243

\title{
Obstacles to Data Sharing in Public Safety Applications Require More Than Technical Solutions Alone
}

Britta Voss

This publication is available free of charge from:

https://doi.org/10.6028/NIST.SP.1243

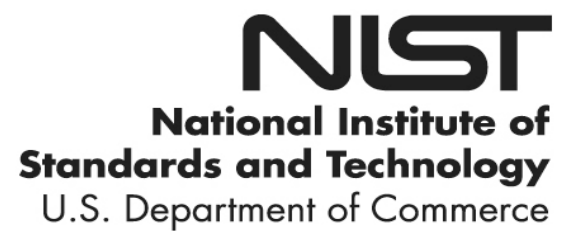


NIST Special Publication 1243

\section{Obstacles to Data Sharing in Public Safety Applications Require More Than Technical Solutions Alone}

Britta Voss

Public Safety Communications Research Division

Communications Technology Laboratory

This publication is available free of charge from:

https://doi.org/10.6028/NIST.SP.1243

September 2019

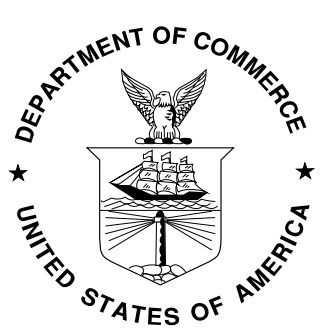

U.S. Department of Commerce Wilbur L. Ross, Jr., Secretary

National Institute of Standards and Technology Walter Copan, NIST Director and Undersecretary of Commerce for Standards and Technology 
Certain commercial entities, equipment, or materials may be identified in this document in order to describe an experimental procedure or concept adequately. Such identification is not intended to imply recommendation or endorsement by the National Institute of Standards and Technology, nor is it intended to imply that the entities, materials, or equipment are necessarily the best available for the purpose.

National Institute of Standards and Technology Special Publication 1243 Natl. Inst. Stand. Technol. Spec. Publ. 1243, 25 pages (September 2019) CODEN: NSPUE2

This publication is available free of charge from: https://doi.org/10.6028/NIST.SP.1243 


\begin{abstract}
First responders today can leverage large quantities of multimedia data from a variety of sources within and outside their agencies, and the scope of this data sharing is growing rapidly. This expansion in capabilities comes with several technical challenges, such as the need for new interoperability standards and software tools that can make sense of the deluge of data. But many of the challenges facing public safety agencies using or considering implementing such technologies are not primarily technical in nature. In areas of governance, policy, and funding, new data sharing technologies exacerbate existing obstacles, such as resource limitations, and create new ones, such as legal risks of cybersecurity vulnerabilities. Through an analysis of responses to structured interviews with first responders across the United States, we summarize the key non-technical challenges facing public safety use of emerging data sharing technologies. Based on the experiences and concerns shared by these first responders, we conclude that addressing these challenges with research and development on technical solutions may help ensure that these technologies deliver maximum benefit for emergency response applications.
\end{abstract}

\title{
Keywords
}

Communication; interviews; policy; public safety; telecommunications; data sharing. 


\section{Table of Contents}

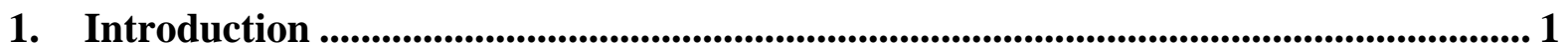

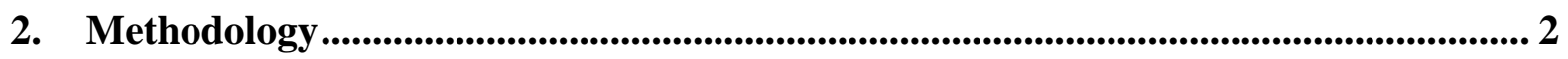

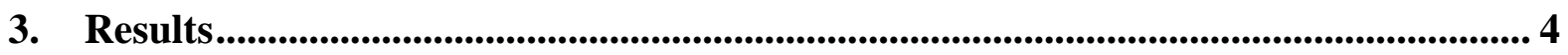

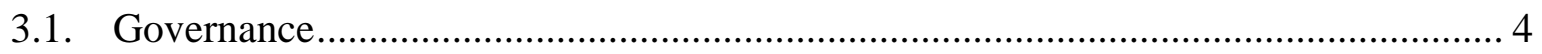

Silos between public safety agencies, jurisdictions, and disciplines............................... 4

Silos between public safety and external partners (private businesses, other government agencies, private ambulance services, hospitals, nonprofits, and courts)........................... 6

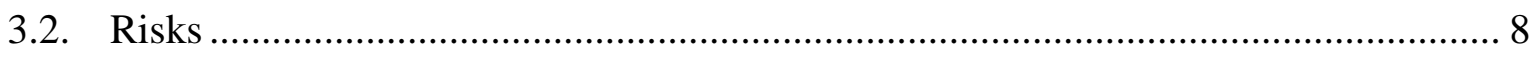

Legal liabilities associated with data collection, use, or misuse ....................................... 8

Difficult to meet policies/best practices of data management.......................................... 10

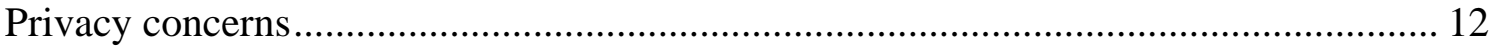

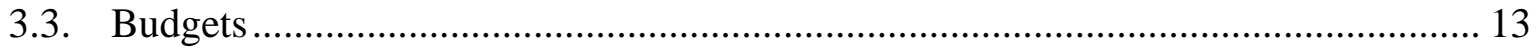

Technology implementation can be cost-prohibitive ....................................................... 13

Difficult to coordinate funding across disciplines and jurisdictions ............................... 14

Shortage of proficient technical personnel ..................................................................... 15

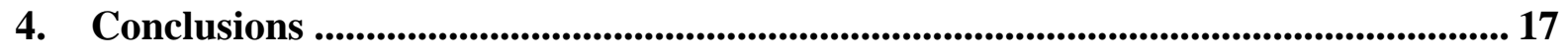

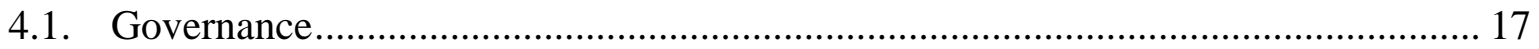

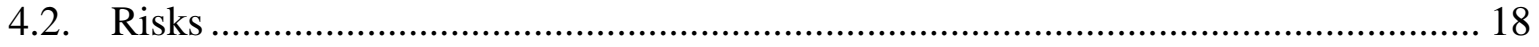

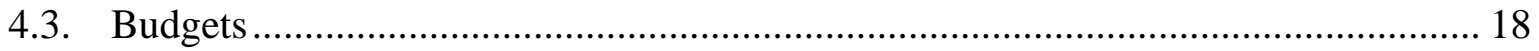

References......................................................................................................................................... 19

\section{List of Tables}

Table 1. Subset of the NIST "Voices of First Responders" codebook ....................................... 2

Table 2. Keywords used to annotate first responder interview data. ...................................... 3

Table 3. Frequency of keywords applied to first responder interview quotes. .......................... 4 


\section{List of Acronyms}

CAD Computer Aided Dispatch

COMMS Public Safety Telecommunications

DOL Department of Licensing

EMS Emergency Medical Services

FF Firefighting

HIPAA Health Insurance Portability and Accountability Act

IT Information Technology

LE Law Enforcement

MDC Mobile Data Computer

NIST National Institute of Standards and Technology

NPSBN National Public Safety Broadband Network 


\section{Introduction}

In this paper, we describe the issues and concerns first responders shared surrounding the use or potential use of emerging data sharing technologies such as mapping and location tracking tools, health and environmental sensors, networked video cameras, and many other applications, as well as analytics platforms that turn large quantities of data into actionable intelligence. While these technologies have already provided significant operational benefits to some agencies and promise to become increasingly powerful in the coming years, many challenges are emerging that may significantly impede the adoption of new technologies and the realization of maximum utility from these tools.

The public safety community traditionally consists of five core disciplines: firefighting (FF), emergency medical services (EMS), law enforcement (LE), and public safety telecommunicators (COMMS). For a given incident, beginning the moment an emergency occurred, to the 911 call, to arrival and response of first responders, to long-term monitoring or investigation, many other entities outside of FF, EMS, LE and COMMS may exchange information with first responders. Thus, the effectiveness of communications technologies depends not just on the actions and processes of first responders, but also on those of numerous public safety partners, including other government agencies, hospitals, courts, schools, nonprofit organizations, private businesses, and many others.

This report presents key issues associated with the use of data sharing technologies in public safety which are not technical in nature. The National Institute of Standards and Technology (NIST) Information Technology Laboratory's (ITL) Visualization and Usability Group conducted extensive interviews with first responders focused on their experiences with communications technologies [1, 2]. Many of the challenges described by the respondents addressed obstacles and concerns that cannot be solved through technological enhancements alone. While more user-friendly or efficient devices and programs may increase the value of emerging communication technologies, they are unlikely to make technologies more accessible to agencies without adequate inter-agency governance structures or technicallytrained staff. For example, issues with device functionality and ergonomics or network reliability are best addressed through continued investment and refinement of existing research and development programs by academic, government, and private sector parties. In contrast, developing cross-jurisdictional governance bodies, technology policy best practices, and new procurement structures calls for comprehensive, public safety-wide strategies. Such solutions require expertise and input from stakeholders across the public safety community, as well as from partners beyond the traditional boundary of public safety [3].

Addressing these kinds of challenges requires a re-evaluation of institutional structures, policies, and funding processes. While the Usability Group interviews did not target such issues directly, the breadth and consistency of the non-technical challenges articulated by first responders provide a foundation for understanding high-priority issues that could be addressed to make emerging technologies for public safety as effective as possible. By highlighting such issues in a standalone report, this report aims to spur discussion and creative thinking among stakeholders within and outside the public safety community and accelerate progress towards solving them. 


\section{Methodology}

This report is based on the transcripts of structured interviews with approximately 200 first responders conducted by the NIST Usability Group during fiscal years 2017 and 2018 [1]. The purpose of these interviews was to learn about first responders' experiences with communications technology: their positive and negative experiences and their desires and expectations for future technologies. In responding to the interviewers' questions, first responders identified a wide range of challenges they had experienced using legacy and existing technologies and desired functionalities for future technologies [2]. Although policy challenges and preferences were not an explicit focus of the interviews, many first responders also described experiences of policy successes and failures; they expressed hopes and lessons learned regarding policy decisions for future technologies. We therefore re-analyzed the interview data through the lens of policy issues in order to identify major themes about the interaction of policy and technology in public safety operations.

Beginning with the dataset of all interview extracts coded for the Usability Group study [1], we analyzed extracts tagged with the following codes:

Table 1. Subset of the NIST "Voices of First Responders" codebook

\begin{tabular}{|c|c|c|}
\hline Major Code & Subcode & Code Operationalization \\
\hline Information & Control & $\begin{array}{l}\text { Data, evidence, or intelligence related to an incident or to } \\
\text { work environment/situation: Entity who has the } \\
\text { ability/responsibility to act or pass on information }\end{array}$ \\
\hline Problems & People & $\begin{array}{l}\text { Identification of issues identified by participants related to } \\
\text { doing their jobs: Issues with people }\end{array}$ \\
\hline Problems & Information & $\begin{array}{l}\text { Identification of issues identified by participants related to } \\
\text { doing their jobs: Issues with information (in getting, } \\
\text { receiving, or producing information; situations where there } \\
\text { was too little or too much information) }\end{array}$ \\
\hline Problems & $\begin{array}{l}\text { Policies/ } \\
\text { Procedures }\end{array}$ & $\begin{array}{l}\text { Identification of issues identified by participants related to } \\
\text { doing their jobs: Issues with formal or informal rules and } \\
\text { operating processes and procedures for how things should } \\
\text { be, have been, or are being done }\end{array}$ \\
\hline Rules/Politics & $\begin{array}{l}\text { Priority/ } \\
\text { Influence }\end{array}$ & $\begin{array}{l}\text { Formal or informal guidelines that directly or indirectly } \\
\text { govern the work, expectations, and/or environments of first } \\
\text { responders: Related to priorities of the administration (e.g., } \\
\text { station, local government) }\end{array}$ \\
\hline Rules/Politics & $\begin{array}{l}\text { Policies/ } \\
\text { Procedures }\end{array}$ & $\begin{array}{l}\text { Formal or informal guidelines that directly or indirectly } \\
\text { govern the work, expectations, and/or environments of first } \\
\text { responders: Formal rules and operating processes for how } \\
\text { things operate }\end{array}$ \\
\hline Rules/Politics & Unspoken & Formal or informal guidelines that directly or indirectly \\
\hline
\end{tabular}


Rules for govern the work, expectations, and/or environments of first

Behavior responders: Informal understandings of how things should be done (for example: radio discipline)

Wish List -- $\quad$ Things (funding, information, processes, technology, devices, or equipment) that would facilitate first responders' job

We read each extract in this set $(\mathrm{N}=3,513)$, marked them as either "relevant" or "not relevant,” and assigned one or more keywords to relevant extracts:

Table 2. Keywords used to annotate first responder interview data.

\begin{tabular}{ll}
\hline Keyword & Keyword Operationalization \\
\hline Policy & Policies, laws, or practices governing the use of technology \\
Politics & $\begin{array}{l}\text { Differences in outlook, style, or tradition between disciplines, agencies, } \\
\text { or individuals }\end{array}$ \\
Accepted procedures or metrics governing communication or the use of \\
technology
\end{tabular}

Of the extracts marked as relevant $(\mathrm{N}=515)$, these keywords were observed in the following frequencies: 
Table 3. Frequency of keywords applied to first responder interview quotes.

\begin{tabular}{ll}
\hline Keyword & Extracts Tagged \\
\hline Obstacle & 274 \\
Preference & 179 \\
Interagency & 164 \\
Data management & 161 \\
Policy & 157 \\
Third party & 108 \\
Standards & 76 \\
Financial & 66 \\
Privacy & 63 \\
Access control & 54 \\
Usability & 36 \\
Liability & 31 \\
Staffing & 28 \\
Retention & 16 \\
Politics & 12 \\
\hline
\end{tabular}

Finally, we assessed the relevant extracts through the lens of these keyword categories to identify unifying themes and key ideas expressed by first responders. Following the convention used in the NIST "Voices of First Responders" reports [1, 2], this report displays interview quotes in blue indented blocks of text, attributed with an abbreviation denoting the discipline (FF, EMS, LE, or COMMS), geographic setting (Urban, Suburban, or Rural), and unique numerical code of the respondent.

\section{Results}

We identified three broad categories of issues expressed by first responders regarding policy challenges and concerns associated with data sharing technologies: Governance, Risks, and Budgets.

\subsection{Governance}

\section{Silos between public safety agencies, jurisdictions, and disciplines}

Public safety agencies are governed primarily by their local jurisdiction (typically city or county). This can create obstacles to communication across agencies of different disciplines within the same jurisdiction (e.g., between fire and law enforcement) and across jurisdictional boundaries (e.g., local and federal law enforcement). Additionally, most incidents to which public safety agencies respond are not large, complex incidents requiring support from multiple agencies across a large geographic area. Therefore, even if communication silos are not consciously constructed between different types of agencies, 
first responders are simply less familiar with the policies and procedures required for multiagency response situations. These factors contribute to the difficulties reported by many first responders in these interviews regarding sharing data with other agencies. Many first responders specifically discussed communication barriers between law enforcement and other public safety agencies.

"We have very little to no communication with our police agency. We are able to scan their channel, but I don't think they want us on their channel, and they don't come onto our channel. And that's been identified as a huge problem in some of these large-scale incidents around the country of, for instance, the [highly publicized incident]. There was no communication between the police and the fire on one scene. So I think that needs to get bridged. I think that's done through policy and procedure. I think the technology is there. I just don't think we utilize it efficiently.” (EMS-S006)

“And the only time we really ever see Park Police's camera is during major events when they allow us access to the video. So it's not something that's immediately accessible on a day-to-day basis.” (FF-U-043)

"[T]hey're trying to create a standard. But to do that all across the United States is almost [tough?] because you got to look at data back in the history of years past. And you might have done yours in Excel, and he did his in DOS, and I just did mine on paper. So there's really no set system... we have different software programs, but none of them communicate with each other. So it's just a lot of data entry.” (FF-S022)

"Most of the agencies out there all have different systems and I think it would be nice to have something across the board that had all the functions that are user friendly. There are different computer systems out there; like the one that we have currently is pretty user friendly; it's real easy to use, it has kind of a lot of new features, one that they might go to if there is a merge with [another jurisdiction], that it is still going to go to a different system that is not as user friendly and doesn't have the features that the current one has and we will have to learn a brand new one over again that is not going to have the same features, not gonna be as good, in my opinion, because it is not going to - we are gonna lose the functionality that we had before that we took for granted, like the large database of names and stuff that we already have for the downriver area; not in that system anymore, we are not gonna have that anymore." (LE-S-064)

"[O]ne thing that we could do better on is our governance and risk management compliance while adopting new technology. I know most of the organizations in the county kind of have a little technology committee or whatever but I don't think those committees share information. And I would like to have standardized-- a standards committee for technology across the board.” (COMMS-S-001)

"I guess, if this is all related towards the technology side, is how much control the government has to force people to follow processes so that we make sure that we're not falling behind the technology curve, or that we're doing the right thing. ... So what 
kind of checks and balances are the government going to have to force the hand of these different cities to do what they need to do to make sure that we are all meeting the same benchmarks?” (FF-U-043)

\begin{abstract}
"Well, and then just the whole movement of transparency and data sharing. I mean, so we're all, the whole nation-- I'll just speak for-- we're coming out of years and years and years of siloed work. Don't share. Don't share your data; don't share verbally; don't share. Don't even share internally, right?” (LE-U-032)
\end{abstract}

Summary of quotes:

- Firefighters and EMS personnel cannot communicate directly with law enforcement officers. (EMS-S-006)

- Park Police only provide local agencies with video data during major incidents, not everyday activities. (FF-U-043)

- Every agency has been using their software systems for many years. Rather than standardize them all, data are manually transferred from one system to another. (FF-S-022)

- Merging with an agency using a different data system means giving up the preferred features of the existing system and having to learn how to use a new system. (LE-S-064)

- There is a need for county-wide coordination and standards to facilitate implementation of new technologies. (COMMS-S-001)

- Government oversight may be needed to ensure all agencies meet certain technology benchmarks. (FF-U-043)

- The shift towards data sharing and transparency goes against many years of information restriction policies. (LE-U-032)

\title{
Silos between public safety and external partners (private businesses, other government agencies, private ambulance services, hospitals, nonprofits, and courts)
}

Responding to large, complex incidents sometimes involves sharing information with entities outside the traditional boundary of public safety. Other government agencies, such as transportation, emergency management, education, and health departments, can provide valuable incident data to first responders. Law enforcement routinely shares data with attorneys, corrections, and other components of the legal system. Fire and EMS regularly share data with private ambulance services, hospitals, and non-emergency healthcare providers. Private companies and nonprofit organizations can also provide incident data to first responders, for example surveillance camera footage, building floorplans, patient data, and facility hazard information. These non-public safety entities have their own internal data systems that are often not interfaced with public safety data systems. Sharing information quickly can therefore be extremely inefficient for first responders.

"Let's say a plane crashed. We have 100 people. If we have that information. I would like that we would be able to send it to [the Red Cross] immediately, without-- 
because the hospitals, you start bringing patients, and then all of a sudden they're setting up their own makeshift triage area for these specific victims alone. And then if you say that, you put all the information. I'm going to the [local university], and you hit tap down, and notify Red Cross, it would be great that that patient information would pop up to the disaster coordinator [local university]. So they have it when we get there. They know we're coming with that person. And they know that the Red Cross has been notified.” (EMS-U-009)

"Sometimes we'll get a printed out, jumbled sheet of information that a healthcare provider-- like, if it's in a nursing home, they'll hand us this jumbled package of information about the medication this person's taking, and some basic history, but that's about the extent of it, and it's not presented in a way that's standardized or useful to us.” (FF-S-032)

"[I]f we could transmit from the field to the hospital so when we got there all they had to do was say, "Oh, Mrs. Jones. Okay. Right. So you're here. You have left side abdominal pain. It's been going on for 10 hours. You took a stool softener, nothing helped. And your pain is a 5 out of 10." That would be awesome. Right now we have to literally repeat everything and then the hospital usually asks it again. So patients see it as kind of disjointed, "Oh, I told the ambulance guys that." ... I think we've integrated well between fire units, EMS units. Where we haven't integrated well is between hospitals and the pre-hospital providers.” (EMS-S-016)

“[I]t's all about billing. It's because Medicare, specifically, likes to deny. They look for ways to deny billing. So they have all these codes, and all these different patient types, and all these different things that they want everybody to fit into, and it doesn't work that way. People aren't numbers. So there's a lot more drop boxing stuff into stuff in order to make it successfully billable. ...and less focus on just making it something that I can do that's accurate, legal, but also concise. And I can get it done in 15 minutes instead of 25. It makes a big difference.” (EMS-R-007)

"[T]his one system that we're looking at actually will allow us to when somebody calls in from their cell phone doesn't know where they are they're in the back country we can send them a text that says push this that says it's okay for me to look at your phone or find your phone basically so it's a find your phone and then you can zoom in on that phone's location and even track them if they're moving so and that's the kinds of things that you know we need in today's society of mobile phones." (COMMS-R-008)

"It can take 20 minutes to trace a phone because we're going through the cell company. The cell company has to then ping the phone it just takes forever you know we don't have that ability so even if you're having a life-threatening emergency we got to wait 20 minutes for them to fill out their paperwork in order for us to get help to you.” (COMMS-U-006)

"So I also have the third party compliance software called [Software Name]. We worked with them and we built a lot of triggers, we also built triggers for the health department. So there's things they watch during the year, such as heat emergencies 
during the summer, cold emergencies. Right now it's narcotic overdoses we're looking at, anytime those things come up, and they'll trigger in [Software Name] and they'll be able to go in and get that data out of our CAD immediately and by going through that third party there's no HIPAA data exchanging, all that stuff's clean..." (COMMS-R-020)

\begin{abstract}
"We're in an active situation or active high-priority situation or high-risk situation, and we're like, "We need a description." So if you already have a picture that came through, and it gets sent out to all our computers or whoever's on patrol, because that's what they'll do is they'll send the DOL photo, drivers license to the MDCs, and they'll throw. So we all have that picture. So we kind of have an idea. It might not be the picture of him that day, but it's going to be who that person is. So if somebody on the street that's called 911 gets a video or photo and can upload it immediately somehow and then they have a photo of him that day with the clothing he's wearing, that would absolutely be helpful." (LE-S-027)
\end{abstract}

\title{
Summary of quotes:
}

- There is a need to seamlessly share patient data with the Red Cross and other non-public safety agency medical responders. (EMS-U-009)

- Patient data provided by nursing homes is disorganized and not standardized, and therefore hard to use. (FF-S-032)

- Patient data obtained by fire and EMS personnel should be immediately available to hospitals to avoid redundancy and improve patient experience. (EMS-S-016)

- For Medicare billing, patient data needs to be fit into codes that don't necessarily match reality, which makes incident record-keeping less accurate and efficient. (EMS-R-007)

- Telecommunicators are interested in the capability to request access to a caller's mobile phone location data. (COMMS-R-008)

- Obtaining mobile phone location data from commercial wireless providers is too slow and cumbersome. (COMMS-U-006)

- Being able to seamlessly share data between the health department, a computer aided dispatch (CAD) system, and a data analytics platform is useful. (COMMS-R-020)

- It would be helpful to supplement images of individuals from government databases (such as driver's license data) with image or video data provided by a 911 caller. (LE-S-027)

\subsection{Risks}

\section{Legal liabilities associated with data collection, use, or misuse}

Many first responders expressed concerns about the liabilities associated with the collection and sharing of data, particularly data which was previously not available. If information exists about an incident, there may be an expectation that it be properly used for decision- 


\section{making. What are the consequences of ignoring data or applying it inappropriately? Some first responders expressed concerns that the adoption of new technologies would require them to interpret and act on information that they are not properly trained to handle or cannot realistically be expected to process.}

"When I worked at [county] they had that they didn't know they could track people's speed and stuff and the issue is when you start tracking that you incur a liability with that where if you don't monitor it and then somebody has an accident and you know it was issued then you know you can be held liable for it whereas if you never had the data to start with you're not incurring that liability.” (LE-R-048)

"I think we're getting closer to being overwhelmed. From a liability standpoint, there's too many things that we're telling the guys you have to do, that if they forget to do one of them, forget to use one piece of technology, and it comes back on them in a negative aspect. I guess that's my concern, of keeping it efficient enough and reasonable enough.” (LE-R-019)

"You just have to make certain that at administration level, departments put in good policy so administrators can't go on a "fishing expedition" to try and find an officer saying something inappropriate or doing something inappropriate.” (LE-S-033)

"I think that the addition of having such intense technology is intimidating to those who were maybe skating by or the thought that now they might be of the mind-set where like, "Oh my God, well I could get caught for what if I didn't do that or--?" And it makes them fearful. So now that technology is causing anxiety because they're wondering, "Oh, am I going to get in trouble? I didn't send that run. They're going to know."” (EMS-U-009)

"I think that being able to mine the data that we already have access to that's public in nature to help people is probably one of the good things that I'm seeing. I'm just really leery of that because of the civil liberties.” (COMMS-R-016)

"If you get so far out of your car, or just as soon as you leave your car, the main system knows you've exited and it's going to turn on your body camera. Or if your lights are on, it can tie into that, and it knows that's probably a traffic stop or high-risk thing. I shouldn't have to stop and think, "Oh, yeah. Turn on my camera." As soon as I leave my car, the body camera should come on if that's our department policy to use body cameras on all calls.” (LE-R-019)

"[T]hat's the challenge that I see because if you're not sitting in that chair, dispatching, taking calls, well we can give that to communications as always a--but as you can see out here they have 5 computer screens in front of them. What does the technology do? Does it increase their workload, their responsibility, their--and with responsibility comes liability? Does it increase that or does it decrease that? Or is it kind of a neutral that this is going to be something new but it's going to help you take some of that workload off but it's going to replace that so is it going to be a neutral or is it going to be something that's going to increase their workload?” (COMMS-R016) 


\section{Summary of quotes:}

- If an agency tracks motorist speed and an accident occurs, the agency could be held liable. (LE-R-048)

- Officers must monitor an overwhelming amount of information, and if they miss something, they could be held liable. (LE-R-019)

- Policies are needed to ensure that technology is not used to go on "fishing expeditions" for bad behavior. (LE-S-033)

- EMS personnel are anxious about using monitoring technologies that could be used to reprimand them. (EMS-U-009)

- The ability to search publicly available data for public safety purposes may compromise civil liberties. (COMMS-R-016)

- Technology should be able to automatically detect when policy dictates a body camera must be turned on. (LE-R-019)

- New technologies can improve outcomes, but they can also increase workloads and create liabilities. (COMMS-R-016)

\section{Difficult to meet policies/best practices of data management}

Agencies are managing more data every day. Once data are collected, what obligations exist for retaining, redacting, or destroying the data? Even if there are clear answers to these questions, in many cases, guidance on how to implement such requirements does not yet exist. Data management involves difficult trade-offs between saving as much information as possible and the cost of long-term, secure data storage.

"We've had just a couple of officers that use body cameras and then submit their video, and it's gigabytes and gigabytes of data that just... and that's just like one or two calls from like an hour or two. And then the question is, do you go lower quality in order to get more, less storage. But I disagree with that. I think it should be the highest quality you can and-- I don't know. And then retention, it comes down to retention of how long do you have to keep things?” (LE-S-021)

"We haven't had any, you know, but when you talk about, you know, the capabilities of the phone, you can take pictures and so forth and you know, although the department discourages using your own cell phone for, you know, evidence pictures and so forth, you know it sometimes just becomes a necessity.” (LE-R-060)

"And there's a communication flow that has to happen and it's really challenging. It has to go from your very local jurisdiction up to your operational area, and it has to get processed and synthesized and say, "Okay, what's the scope of this," right? And it's much more detailed information than you would get like, "Hey this building is on fire." Okay? "Let's all run and put it out." Well now you've got to go back and you've got to have building inspector information. You've got to have-- how much timekeeping that's involved? All these different components of information that make that 
process a lot more complex. And then you have to account for it, right?” (COMMS-S001)

"Some of the things talking about videos and pictures with that -- and we know that that is coming but I don't think that should be something that is law delivered anywhere. You know, I don't care whether it's New York City or Boise, Idaho, and I think any of that technology should be something that the person sitting behind that console has the option to say -- yes, I want to see this or Ms. Supervisor, I need you to view this. You know, I am just talking about the whole mental viewing that -- I don't think that that should something that when we answer 911, that there is something that pops up in front of somebody's face...” (COMMS-R-019)

"So if you call 911 because you're having chest pain, and the 911 dispatcher's asking you all kinds of questions about where do you live, and what's your address? Where are you at in the house? What time did your chest pain start? Just being that dispatcher asking questions, those are all same questions that I'm going to have to ask when I get there. And I don't know them-- and I don't know them ahead of time. So they're already getting them, and they're staring at a computer. I would find it helpful if those questions that they asked, when they got put into the dispatch message, that they would also transfer...Push to me and also transfer over to my electronic reporting mechanism.” (EMS-S-015)

"Speaker 1: [W] have an inventory software that we can track when we bought [a lifeline rope], and we can track when we throw it away. But the only way to track all the stuff in the middle is a piece of paper.

"Speaker 2: So once that form fills out, you have no idea every time it was used before.

"Speaker 1: And then there becomes the problem of you have to archive it. So do you archive it in a book? Do you archive it as a digital copy? Where do you keep it? ...And then when the accreditation shows up, or when OSHA shows up because there's a problem - somebody fell off a rope or something - now you have to dig all this stuff out.” (FF-S-022)

\section{Summary of quotes:}

- There is a tension between retaining enough data for high-quality video and managing huge quantities of data, while complying with retention policies. (LE-S-021)

- Prohibiting the use of personal phones for on-duty work is sometimes impractical. (LE-R-060)

- Detailed building data are needed to understand the scope of a fire and assign appropriate resources, and this information is not efficiently organized. (COMMS-S-001)

- Video and image data provided by 911 callers should not automatically be presented to 911 call takers. (COMMS-R-019) 
- All information collected from a 911 caller by a 911 call taker should be provided electronically to EMS personnel. (EMS-S-015)

- There are no formatting standards for equipment records required by federal regulators. (FF-S-022)

\section{Privacy concerns}

Data collected for emergency response can expose both first responders and members of the public to privacy risks. Many first responders expressed ambivalence or wariness about the prospect of being recorded or tracked while performing their work duties. While many acknowledged that such technologies could provide operational benefits, many were also concerned about the potential for their use to punish first responders. At least one first responder also acknowledged the potential privacy risks to the public as a civil liberty issue. The public may be unaware of what data about them or their community are available to first responders, and presumably hold a variety of opinions about whether and how such data use should be constrained.

"As I told people when we put the license plate recognition cameras on the cars and they had GPS tagging for the photos, everyone thought I was following their cars or I was tracking their cars. They were cutting my CAT 5 cables for fear that these things would work, and that they would be caught doing something they weren't supposed to be doing, which for the most was going outside of their sector or outside of their district, not outside the city, just crossing a street into another district. Some would say would be a violation of rules and procedure. So they were very reluctant to allow a device in the car that would allow me to track that.” (LE-U-011)

"They've had officers when they had a police shooting, they were using their personal cell phones and they subpoenaed to get copies of the entire cell phone. So there's kind of the whole privacy thing, which is why I think the department's moving to-- here's the department phone. Do not use yours, otherwise anything you have on their, personal, private, it can be shared.” (LE-U-024)

"I think also if there was a way to, on the reverse side, bringing in a patient that we're trying to describe what's wrong with them, or how they look, or how concerning they are, or how non-concerning they are despite their complaint or maybe one of their vitals is abnormal but you're like, "No, this is just drama." And then, but if we could show that to the receiving hospital, like, "Look, they're fine," or, "Look, you better open up a front room and get a bunch of doctors in there." So I think seeing-- there's a privacy thing now where, do I want to be on camera on every single call that I'm on? Probably not. Do I want to be on camera on any of the calls I'm on? Probably not. But do I run every call like somebody is filming me? Yes, I do, because they're everywhere. So it could be useful to see stuff.” (EMS-R-007)

"Well, the video stuff is always nice to be able to have, just that where-are-they kind of a tracking, keeping accountability. It's like all these things come with just privacy issues too, though. We're trying to figure out how to balance.” (FF-R-019) 
" $90 \%$ of our calls are wireless. So, if they are calling in -- then maybe we would have access to their camera. Like, by them calling 911 would grant us access to let's say their camera... And that way like that would help us if we are having trouble locating -- I don't know where I am at. Okay, well -- let me see where you are at.” (COMMSR-019)

\section{Summary of quotes:}

- Officers do not want to use technology that they think will be used to monitor and reprimand them. (LE-U-011)

- A police department provides mobile phones, so officers do not have to risk exposing their private data by using a personal device for work purposes. (LEU-024)

- Filming incidents could provide useful information, but also creates privacy risks for EMS personnel. (EMS-R-007)

- Filming incidents provides useful incident data and transparency, but also creates privacy risks. (FF-R-019)

- 911 call takers could request access to a caller's mobile phone location data to help locate them. (COMMS-R-019)

\subsection{Budgets}

\section{Technology implementation can be cost-prohibitive}

Public safety agencies work with tight budgets. Adopting a new technology at the scale of an entire agency is expensive. Agencies often find it difficult to justify technology expenses when personnel salary and maintenance of existing equipment are under-resourced. Many first responders commented on their experiences scraping funding together and inadequately funded technology implementations.

\footnotetext{
"We've got one design for body cams, we've got one design for in-car cams, we've got one design for CAD, and then we've got all these other small things. And they're all from different vendors, because of whatever reason. The city was trying to beg, borrow, steal these things from different vendors and they didn't want to pay full price, so none of them integrate well together, which is a huge issue for us.” (LE-U005)

“[S]o standardized patient care records, standardize some ability to a common footprint, blueprint, means to access information about buildings. But the thing is that we're not going to get it from-- I don't believe we're going to get it from the thirdparty system out there that's building it. It needs to come probably from some sort of like-- and there's not an economic motivation to just build something like that. Maybe somebody could build something that's big enough for everybody adopt it, and then you'd have it, but it seems like the more appropriate way is some sort of nationalized standard or government funding or something like that.” (FF-S-032)
} 
“There's no money in it for them [cellular device makers]. It's very expensive for them to upgrade their systems and that's why we currently don't know where you are when you call 911 from a cell phone.” (COMMS-U-007)

"And they believe that we should be providing a phone or some sort of communication to them so that they can communicate easily with their chiefs, and sometimes that's difficult on our side because now we would have to supply phones for everyone and it's just not; money-wise, it's not going to happen.” (EMS-U-010)

\section{Summary of quotes:}

- Acquiring the cheapest equipment from a variety of vendors results in a lack of integration across technologies. (LE-U-005)

- Standardization of patient, building, and other data is needed, but vendors are not economically incentivized to implement standards. (FF-S-032)

- The inability to locate a 911 caller's location from their mobile device is due to a lack of economic incentive for cellular device makers. (COMMS-U-007)

- Agencies want to provide phones to responders but cannot afford to provide them to everyone. (EMS-U-010)

\section{Difficult to coordinate funding across disciplines and jurisdictions}

Budgets for public safety agencies, in addition to being tight, are typically restricted to expenditures for a specific agency. For agencies wishing to collaborate, this can create barriers to cost sharing. Significant budget disparities between agencies can result in a hodgepodge of technologies and software versions across a region, which can stymie crossjurisdictional interoperability efforts.

"Another technology initiative that we saw fail in this valley was the fire several fire agencies were trying to get mobiles in their vehicles and right now there's very limited capabilities for fire to see the important information in their mobiles that law enforcement sees and again it comes down to just lack of funding and ability for them to tie into these calling systems and so I think that interop just isn't radios there's more to it with these officers, these first responders need to have certain information, they don't need to see arrest records and things like that but there's a lot of information that they crave from dispatch and they just don't have any way to get to it because they can't have the tools that are funded by the law enforcement side.” (COMMS-R-008)

"Because you got districts in this county, like us, who are pretty well funded. You get districts in this county, like [town], they are completely volunteer. Their budget is, I mean-- we give them our used equipment because they need it. They have no money to spend on anything, so how are you going to apply technology evenly across even as small an area as our county and make sure that it benefits everybody?” (EMS-R008) 
"They try to get the best stuff and everything is-- again, when you do the technology upgrade, you have to start and then you have to finish. But you can start, but you still have half of the city that is on the old stuff, because it's what? It's budgetary. It's money.” (LE-U-012)

"But I think there's some opportunities in the future as money gets tighter, and that you just can't build fire houses wherever you want anymore. You have to figure out how can we work together to cover areas on the fringes of your protection area." (FFS-017)

\section{Summary of quotes:}

- Lack of interoperability results from the inability to share equipment funding across public safety disciplines. (COMMS-R-008)

- Funding disparities between jurisdictions makes it impossible to adopt technologies evenly. (EMS-R-008)

- Funding disparities makes it hard to keep technologies up-to-date across a whole city. (LE-U-012)

- Jurisdictions must coordinate funding to ensure adequate coverage of an entire protection area. (FF-S-017)

\section{Shortage of proficient technical personnel}

Many first responders commented on the increasing technical requirements associated with emerging communication technologies. Public safety agencies often do not have significant information technology (IT) support in-house or share IT personnel with other government agencies. As the amount and diversity of technologies used by first responders grows, this gap will continue to widen.

"So you want to do this technology, someone's got to monitor it. If you want to have a drone that does a windshield survey of every district in the city, that's great, but the engine company is gone. They're helping people in the collapsed building. Who's going to run the drone? Who's going to look at the video that the drone is producing? Who's going to assess that video and rank it and know what to do and who to give it to and prioritize what you see on it?” (FF-U-016)

"[A] lot of our people here are just-- they don't understand what the possibilities could be. All they know is what we've always done. They have their blinders on. And this is the way we do things." (FF-U-044)

"What happens when it doesn't work? What happens when we have trouble with it? Who fixes it? Because I can't just call downstairs to IT, okay? I've got a contractor that does our IT because we don't have an IT department. They're budgeted two days a week, maybe... [T] here's technologies out there that I'd love to use right now but I refuse to implement because we don't have the-- I don't have the bandwidth, the personal bandwidth, to manage it. For instance, driver monitoring software and 
hardware is a big deal on the EMS industry... If you get grant money for an ambulance, you have to have some kind of driver monitoring system in it. Well, all those things are connected technologies. They all have to be downloaded. They all have to be analyzed. They all have to-- and that's just one technology. That's not the radio system. That's not our patient care reporting system. That's not our scheduling system. It's a whole nother system that somebody has to deal with.” (EMS-R-008)

"So that's probably the biggest key, is do they [IT support] have the capacity to get it done, the work capacity? Because we still have to keep the trucks maintained and all of these systems... So yes and no. Not really. If I had more staff, it would be quicker. Unfortunately, now it's becoming a higher priority, so I might have to kick the can on some other stuff, and try to bring this together.” (FF-S-023)

"I think these are all considerations as they keep adding the stuff and I keep trying to tell my administration, "At some point, you will have to add more support staff." You can't keep adding more and more stuff... without adding someone dedicated to understand how it works and supporting the guys when they have questions about it. Or it's going to get thrown in the back of the car and forgotten and just told, "It's another project that didn't work," because the support wasn't there.” (LE-R-019)

"So, you know, and then we were hiring people to take care of that that can really hold you hostage because they talk in a language that is foreign to me and I don't want to have programmers and people working -- we are law enforcement, so let those folks take care of that. Let us do -- I don't need to be hiring those people working in Sheriff's Office. I need that to be a service that we hire.” (LE-R-058)

"For a long time there-- so we were in a period where we had a deputy fire chief in charge of IT, and I thought he did a really, really good job of bringing us into the future for a lot of this stuff. And they eliminated that position - I don't know how many years now - four, five years ago. Maybe more than that by now. I feel like we desperately need that...” (FF-U-044)

"I'm 52 years old and I really don't want to keep doing what I was doing when I was 20. So this position came open and I migrated to here because I was really the only one that knew the CAD, knew the communications center and all that stuff, so we hired a new so I help him.” (COMMS-R-020)

"It would cost the department not just more money in server space and server upkeep they would have to hire probably one or two more IT guys just to man that [bodyworn camera data]. Plus the equipment upkeep, the contracts and stuff like that that they would have to have with [company] and with [company] or [company] whoever they decided to go to and it just comes down to money really." (LE-R-045)

\section{Summary of quotes:}

\section{- Adding more sources of data requires someone to monitor and filter information. (FF-U-016)}


- Existing staff don't have a vision for potential technological capabilities. (FFU-044)

- Part-time information technology (IT) contractors are not adequate for implementing and managing critical modern EMS technologies. (EMS-R-008)

- More IT staff are needed, but there is no extra staff budget. (FF-S-023)

- Adding new technologies without increasing the number of technical support staff will result in the technologies not being used. (LE-R-019)

- Communication barriers between IT staff and public safety personnel make it hard for the agency to directly manage IT staff. (LE-R-058)

- Agency budget for staff does not adequately support the personnel needed to keep technologies up-to-date. (FF-U-044)

- Transferring existing staff into technology roles creates staffing needs in other areas. (COMMS-R-020)

- Dedicated staff are needed to manage body-worn camera data, maintain equipment, and manage contracts. (LE-R-045)

\section{Conclusions}

In their interview responses, first responders articulated a wide variety of issues that are already inhibiting or may in the future inhibit optimal use of modern data sharing technologies. Many comments linked their observations of public discussions of technologies such as facial recognition and navigation assistants to the obstacles they had experienced or anticipated in using these technologies in their work. This report highlights the challenges expressed by first responders which cannot be solved through technological developments alone. These issues will require cross-disciplinary and cross-jurisdictional discussions and strategies to address. Some obstacles may require creative new approaches that can more effectively address the challenges of new technologies than the traditional locally-based structures of public safety governance and funding.

\subsection{Governance}

First responders across disciplines expressed a need for better cross-agency and crossjurisdictional coordination to get more value out of emerging communication technologies and the NPSBN. While this has been true for LMR and CAD communications for many years, the limitations of not sharing data and not making collective strategic plans will be an even larger obstacle for technologies and networks with no intrinsic jurisdictional boundaries. If groups of agencies and jurisdictions make collective decisions about interoperability requirements for new technologies, they may be better positioned to enforce their requirements and ensure that interoperability is achieved across the full spectrum of stakeholders within and beyond traditional public safety disciplines. Stronger cross-agency governance structures could also help alleviate disparities between agencies with vastly different resources. 


\subsection{Risks}

New data sharing technologies present risks — both existing and potential — that public safety agencies are often unprepared to mitigate. The capability to collect and share a wider variety and larger volume of information presents potential legal liabilities related to what first responders are permitted to collect and what security procedures are required of them. Laws and policies have largely not kept pace with the development of these technologies, so agencies are often left to determine best practices with limited guidance. Emerging data sharing technologies especially raise privacy concerns related to the collection, dissemination, use, and long-term storage of personal information of members of the public and first responders themselves. As public safety agencies consider implementing new data sharing technologies, they could benefit from tutorials and best practice documents developed by technical and policy experts and tailored to public safety use cases. Such informational and guidance resources could be standardized across the public safety community and updated frequently to accommodate the rapid changes in the state of data sharing technologies.

\subsection{Budgets}

First responders described how tight budgets, legal constraints, and inadequate technical staffing present obstacles to achieving cross-agency data interoperability. Agencies regularly struggle with the decision to delay or downscale technology implementations due to lack of resources, which risks inadequate and uneven progress towards data interoperability. In addition to the capital costs of new technologies, agencies need resources to pay for more technical support staff capable of monitoring, implementing, and managing new data sharing technologies. Finally, funding mechanisms that prohibit spending on shared resources represent an impediment to cross-agency data interoperability. First responders expressed the need for flexibility to collaborate and share costs associated with technology implementation. Possible approaches to these challenges could include creating state or regional public safety funding opportunities to bridge the gap between local and federal funding sources and the designation of funding for technical support staff.

\section{Acknowledgments}

This report was made possible through the generous contributions of time from first responders and the members of the NIST Usability Group, especially Mary Theofanos, YeeYin Choong, Shanée Dawkins, Susanne Furman, and Kristen Greene. 


\section{References}

[1] Choong Y, Dawkins S, Furman S, Greene KK, Prettyman SS, Theofanos M (2018) Voices of First Responders - Identifying Public Safety Communication Problems: Findings from User-Centered Interviews Phase 1, Volume 1. (National Institute of Standards and Technology, Gaithersburg, MD), NIST Interagency/Internal Report (NISTIR) 8216. Available at https://doi.org/10.6028/NIST.IR.8216

[2] Dawkins ST, Choong Y-Y, Theofanos MF, Greene K, Furman SM, Steves MP, Prettyman SS (2019) Voices of First Responders - Examining Public Safety Communication Problems and Requested Functionality: Findings from User-Centered Interviews, Phase 1, Volume 2. (National Institute of Standards and Technology, Gaithersburg, MD), NIST Interagency/Internal Report (NISTIR)-8245. Available at https://doi.org/10.6028/NIST.IR.8245

[3] Voss BM, Anderson E (2019) Interoperability of real-time public safety data: Challenges and possible future states. (National Institute of Standards and Technology, Gaithersburg, MD), NIST Interagency/Internal Report (NISTIR)-8255. Available at https://doi.org/10.6028/NIST.IR.8255 